IZA DP No. 8245

Leaving Poverty Behind? The Effects of Generous Income Support Paired with Activation

Simen Markussen

Knut Røed

June 2014 


\title{
Leaving Poverty Behind? The Effects of Generous Income Support Paired with Activation
}

\author{
Simen Markussen \\ Ragnar Frisch Centre for Economic Research \\ Knut Røed \\ Ragnar Frisch Centre for Economic Research \\ and IZA
}

Discussion Paper No. 8245
June 2014

IZA

P.O. Box 7240

53072 Bonn

Germany

Phone: +49-228-3894-0

Fax: +49-228-3894-180

E-mail: iza@iza.org

\begin{abstract}
Any opinions expressed here are those of the author(s) and not those of IZA. Research published in this series may include views on policy, but the institute itself takes no institutional policy positions. The IZA research network is committed to the IZA Guiding Principles of Research Integrity.

The Institute for the Study of Labor (IZA) in Bonn is a local and virtual international research center and a place of communication between science, politics and business. IZA is an independent nonprofit organization supported by Deutsche Post Foundation. The center is associated with the University of Bonn and offers a stimulating research environment through its international network, workshops and conferences, data service, project support, research visits and doctoral program. IZA engages in (i) original and internationally competitive research in all fields of labor economics, (ii) development of policy concepts, and (iii) dissemination of research results and concepts to the interested public.
\end{abstract}

IZA Discussion Papers often represent preliminary work and are circulated to encourage discussion. Citation of such a paper should account for its provisional character. A revised version may be available directly from the author. 


\section{ABSTRACT \\ Leaving Poverty Behind? The Effects of Generous Income Support Paired with Activation*}

We evaluate a comprehensive activation program in Norway targeted at hard-to-employ social assistance claimants with reduced work capacity. The program offers a combination of tailored rehabilitation, training and job practice, and a generous, stable, and non-meanstested benefit. Its main aims are to mitigate poverty and subsequently promote selfsupporting employment. Our evaluation strategy exploits a geographically staggered program introduction, and the causal effects are identified on the basis of changes in employment prospects that coincide with local program implementation in a way that correlates with the predicted probability of becoming a participant. We find that the program raised employment prospects considerably.

JEL Classification: $\quad$ C21, C26, H55, I30, J24

Keywords: poverty, vocational rehabilitation, social insurance, treatment effects, program evaluation

Corresponding author:

Knut Røed

The Ragnar Frisch Centre for Economic Research

Gaustadalléen 21

0349 Oslo

Norway

E-mail: knut.roed@frisch.uio.no

\footnotetext{
" This paper is part of the project "Evaluation of a Norwegian Qualification Program", financed by the Norwegian ministry of labor and social affairs. Thanks to Simen Gaure for invaluable help with estimation. Thanks also to Kristian Heggebø, Ivar Lødemel, Angelika Schaft, and seminar participants in Bergen, Stavanger, and Sydney for comments and suggestions. Data made available by Statistics Norway have been essential for the research project.
} 


\section{Introduction}

How should policy makers design social insurance institutions in order to fight persistent unemployment, marginalization, and poverty? While economists often emphasize the moral hazard problems and the potential lock-in effects arising from generous social insurance programs, there is also an extensive literature focusing on the barriers associated with poverty itself, caused, e.g., by the type of myopic behaviors it promotes and the kind of unhelpful social networks it gives access to; see Dasgupta and Ray (1986; 1987), Dasgupta (1997), CalvóArmengol and Jackson (2004), and Shah et al. (2012). Empirical evidence indicates that severe scarcity reduces the ability to focus and concentrate on issues beyond the immediate needs, and that it deprives sleep, erodes self-control, and reduces work productivity; see Mullainathan and Shafir (2013) for a recent discussion of the literature. Some income support may thus be required to break out of a poverty trap. But since income support is normally tested against earned income, generosity may discourage self-sufficiency and create a benefit trap instead. A potential solution to this dilemma is to couple generosity with activation, effectively removing the leisure-component from a life on income support, and also ensuring some "maintenance" of basic employment-skills. Properly designed, activation requirements facilitate more ambitious social programs without aggravating moral hazard problems; see, for example, Moffitt (2007) for a review of empirical evidence in relation to the introduction of activation requirements in the cash-based welfare program for single mothers in the US, and Røed (2012) for a recent survey of the literature regarding activation strategies in unemployment and disability insurance programs.

In the present paper, we evaluate a "Qualification Program" (QP) that was launched by the Norwegian government in 2007 as its major tool to fight poverty. The program is both costly and ambitious, and designed to combine generosity and activation on a hitherto unprecedented scale. It is targeted at persons with severely reduced earnings capacity and no or very limited social insurance entitlements. The typical recruitment base is persons who have become, or are in danger of becoming, completely reliant on means tested social assistance (welfare). QP participants may have a variety of problems in relation to a competitive labor market, such as poor language skills, disrupted schooling, little or no work experience, and sometimes mental disorders and drugs problems. Around half of them have a minority background. The aim of QP is to help these often hard-to-employ persons into self-supporting employment through an individually tailored activation program under which they also receive a standardized (and not means-tested) income support amounting to 170,000 NOK (approximately 28,000 \$) per year 
in 2013 (113,000 NOK for participants below 25 years) plus child allowances and housing benefits. For the average participant, this implies a significant increase in total income, from 154,000 NOK $(26,000 \$)$ in the last whole calendar year prior to entry to 240,000 NOK $(40,000 \$)$ in the first calendar year after entry. ${ }^{1}$ It is notable that the QP benefit is paid out by the local municipality's pay office rather than by the local welfare office, it is taxed like regular labor earnings and also entails the same holiday and leave privileges. The motivation for all this is to minimize the shame and stigma associated with participating in the program, and thus to reduce the risk of social isolation and withdrawal from networks that may be of importance in the process of breaking out of poverty; see, e.g., Walker et al. (2013). Claimant interviews have indicated that this is appreciated by the participants, and that the laborearnings-like payment does represent a source of dignity; see Gubrium and Lødemel (2014). The QP benefit is normally granted for a period of up to two years, but additional extensions can be given on the basis of an individual assessment. In return, the participant is expected to take fully part in a tailored qualification and activation plan agreed upon by the claimant and the caseworker. Failure to do so - without justifiable cause - immediately results in a corresponding pay cut. The contents of the participation period vary a lot, but are normally made up of a combination of consultations, employment-training, medical rehabilitation or therapy, social training, and skills-upgrading. Large administrative resources have been set aside to ensure that the caseworkers have the capacity needed to follow up their QP clients, and, hence, to ensure meaningful program activities. Statistics reported by the Norwegian Labor and Welfare Administration (NAV), indicate that each QP caseworker on average has 18 clients. By comparison, caseworkers dealing with the temporary disability insurance program on average have 86 clients.

An important concern in the design of QP has been to achieve an appropriate balance between individual rights and responsibilities. One could perhaps say that the basic idea of the program is to offer income safety and stability, and require a genuine effort to become self-sufficient in return. Based on the existing literature, it is not clear how we would expect this strategy to affect the participants' future employment and earnings prospects. On the one hand, the program raises overall benefit levels considerably, and it does so for a relatively long period of time. There is ample empirical evidence showing that more generous social insurance has negative effects on labor supply, ceteris paribus; see Krueger and Meyer (2002) for an overview of the literature, and Røed and Zhang (2003; 2005), Fevang et al. (2013), and Kostøl and

\footnotetext{
${ }^{1}$ These numbers are computed from administrative register data presented later in this paper.
} 
Mogstad (2014) for recent Norwegian evidence. On the other hand, QP requires full-time participation in a tailored activation program. There exists no general consensus regarding the overall impacts of activation. For unemployed job seekers, the typical findings are that there are favorable "threat effects" prior to active labor market program participation, adverse “lock-in-effects” during participation, and then (sometimes) favorable "post-program-effects" afterwards; see, e.g., Kluve et al. (2007) and Card et al. (2010) for recent reviews; and Raaum and Røed (2006) and Røed and Westlie (2012) for Norwegian evidence. There is also a literature focusing on programs specifically targeted at temporary disabled persons, but with a few notable exceptions - Frölich et al. (2004) and Aakvik, et al. (2005), which have indicated effects close to zero for Sweden and Norway, respectively - this literature is more oriented toward comparing the effects of alternative rehabilitation strategies than toward evaluating the more general effects of applying an activation strategy as an alternative to pure income insurance.

The program we evaluate in the present paper is, to our knowledge, unique in its combination of generosity and (tailored) activation for a hard-to-employ target group with little (or no) social insurance entitlements. It represents a coherent - yet untested - strategy to fight persistent poverty. Fortunately, the program is also unique in that it was implemented in a way that facilitates scientific evaluation; i.e., it was phased in gradually over a three-year period, implying that potential participants got access to it at different points in time. In this paper, we develop a novel evaluation strategy where we combine the staggered program implementation with observed proxies for "participation propensity” to identify the causal impacts of QP participation on subsequent labor market outcomes.

Our main finding is that the program has been successful in terms of helping hard-to-employ persons into employment. Four years after program entry, we estimate that QP participation on average raises the employment rate by around 18 percentage points, ceteris paribus. Most of the extra employment comes in the form of poorly paid and/or very small jobs, however; hence, the dependency on transfers from the welfare state remains high.

\section{Institutions and data}

The Qualification Program (QP) was launched in November 2007, and then rolled out gradually over the next three years -municipality by municipality - in tandem with an administrative reform that merged the local employment and social insurance offices into new joint ad- 
ministrations (NAV); see, e.g., Christensen et al. (2013). By January 2010, QP had become a nationwide program. Although the empirical strategy we are going to use in this paper does not rely on a random-assignment-like order of local implementation, it is worth noting that the implementation-sequence was determined primarily on the basis of administrative considerations in relation to the establishment of the new NAV-offices, and not on the basis of, say, local employment opportunities.

QP is designed to support persons who fall between the two stools of employment and social insurance, and thus potentially face serious poverty problems. The aim of the program is to provide a stable and safe economic basis over a 1-2 year period, while at the same time helping the participants onto a steady path toward self-sufficiency. The legislation states that "the Qualification Program applies for persons of working age with substantially reduced work and income capability and no or very limited social insurance entitlements” ( $§ 29$ in the Law of Social Services in the Labor and Welfare Administration; our translation). It further states that entitlement also requires that a) the applicant's work ability has been assessed, b) that the program is viewed as both appropriate and necessary in order to increase the applicants' possibilities for labor market participation, and c) that the Labor and Welfare administration is able to offer a suitable program. Given that these (somewhat vague) requirements are met, access to QP is a legally protected entitlement. The provisions of the Act state that the duration of the program is to be determined individually. Formally, the QP benefit is granted for one year at a time, but during the period covered by our analysis, a two-year perspective was stated as the main rule. Based on an individual assessment the program can also be extended beyond two years, provided that the claimant has shown progress in his/her efforts to qualify for the labor market and that a transition to employment appears probable within the near future. The program may be terminated at any time if the participant does not fulfill the obligations set out in the individual plan, or if he/she succeeds in finding regular job.

For the target group of QP, the alternative help offered by the welfare state will typically be means-tested social assistance or, in cases of serious and lasting health problems, a temporary or permanent disability insurance benefit. For most of the participants, the program represents a considerable rise in personal income at the time of entry. Hence, from a pecuniary point of view, the program is typically viewed as attractive. QP has therefore not been considered useful as a willingness-to-work test whereby caseworkers threaten to terminate social assistance if participation is rejected. To the contrary, it has been emphasized that participation in QP is 
voluntary, and should be considered a privilege rather than a duty. In that sense, QP is more a "carrot" than a "stick".

Participation in QP entails a fulltime activity of some sort, based on an individually tailored plan. If the participants nevertheless have additional earnings during the participation period, the QP benefit is reduced in proportion to the work-hours outside the program, such that, e.g., a half-time job results in a 50\% reduction in the QP benefit.

Based on reports collected from the municipalities, the Norwegian Labor and Welfare Administration (NAV) has counted that 17,214 persons had participated in QP by the by the end of 2010, out of which 4,968 had then completed the program according to the individual plan and 1,414 had dropped out (Schafft and Spjelkavik, 2011). Among those who had completed the program, $31 \%$ were reported to have obtained regular employment afterwards, whereas 7 $\%$ entered regular education. The rest continued receiving some kind of income support, either in the form of temporary or permanent disability insurance or in the form of social assistance.

The data we use in the present analysis are collected from administrative registers and comprise in principle the whole Norwegian population. Information on individual participation in QP is based on a separate code for QP benefits used on the paycheck submitted for each participant by the municipalities to the tax authorities. This way, we can identify the year of program entry and also the years of continued participation, but not the exact starting and stopping dates. By means of encrypted identification numbers, we merge these data to several other administrative registers containing a wealth of information on individual characteristics (like gender, age, education, nationality, municipality of residence) as well as longitudinal information on past and future employment and income sources. From these data, we compute person-year-observations on several outcomes, particularly related to employment, earnings, and social insurance dependency.

Based on the procedure described above, we identify 19,211 participants from 2008 through 2011, which is roughly in line with the numbers reported (manually) by the municipalities to the Labor and Welfare Administration. The number of entrants was largest in 2009 and 2010; see Table 1 . This table also shows that many participants remain in the program for more than 
two years. ${ }^{2}$ Figure 1 presents some key descriptive statistics for the participants identified in our data - in terms of their labor earnings, their employment propensity, and their claims of (taxable) social insurance benefits and (non-taxable) means-tested social assistance (welfare) in a period from 8 years before till 3 years after entry into QP. These statistics all indicate that entry into QP coincided with a marked turning point in economic outcomes for the participants. Prior to the year of QP entry, the participant group members had experienced a steady decline in average employment and labor earnings during the whole 8-year period covered by our data, and a corresponding rise in the dependency on means-tested social assistance. In the years after entry, these trends were significantly reversed. Moreover, from the year of entry, the level of taxable benefits also rose markedly, basically reflecting that the QP benefit itself falls into this category.

Table 1: Descriptive statistics for participants in QP

\begin{tabular}{lc}
\hline Number of participants & 19211 \\
Entry year & \\
$\mathbf{2 0 0 8}$ & $2,919(15.2 \%)$ \\
$\mathbf{2 0 0 9}$ & $5,857(30.5 \%)$ \\
$\mathbf{2 0 1 0}$ & $6,060(31.5 \%)$ \\
$\mathbf{2 0 1 1}$ & $4,375(22.8 \%)$ \\
Still participating & \\
$\mathbf{1}$ year after entry year & $82.9 \%$ \\
$\mathbf{2}$ years after entry year & $49.8 \%$ \\
3 years after entry year & $23.1 \%$ \\
Mean age & 33.7 years \\
Female \% & $44.0 \%$ \\
Non-native \% & $50.7 \%$ \\
High school \% & $16.1 \%$ \\
College/University \% & $7.0 \%$ \\
\hline
\end{tabular}

Note: Statistics are based on all QP entrants from 2008 through 2011. Participation rates 1-3 years after entry are based on entrants than can be followed for the period in question, with data ending in 2011. For example, participation 3 years after entry is based on 2008-entrants only.

Figure 1 certainly conveys the impression that the QP program must have had large positive impacts on the participants' employment and labor earnings trajectories. Note in particular, that the pre-program decline in labor earnings and employment not at all resembles the notorious “Ashenfelter Dip” (Ashenfelter, 1978) whereby the deterioration occurs just prior to program entry and, hence, foreshadows a reversion "toward the mean” in the near future regardless of program participation. To the contrary, the pre-program decline appears to have

\footnotetext{
${ }^{2}$ Since we do not have exact starting and stopping dates, we cannot compute accurate durations, but the numbers in Table 1 indicate that around $50 \%$ of the participants are in the program in at least three consecutive calendar years, and $23 \%$ are participating in at least four years.
} 
been a consistent feature of the participants' economic fortunes for many years, perhaps indicating that the decline would have continued in the absence of program entry.

(a) Labour earnings

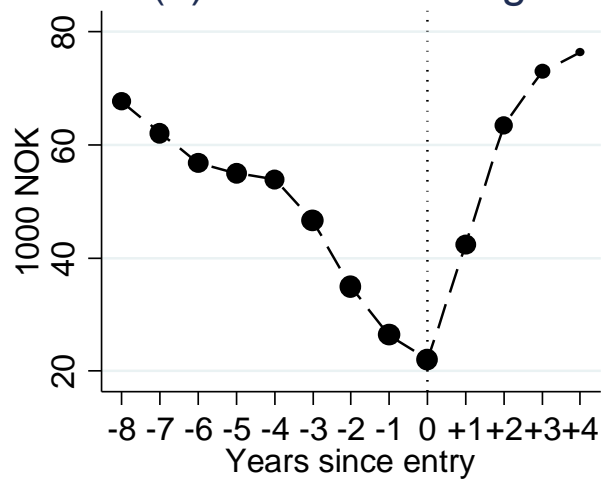

(c) Taxable benefits

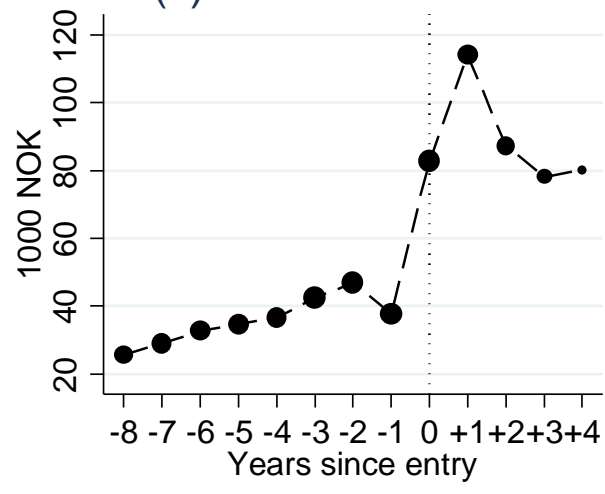

(b) Employment

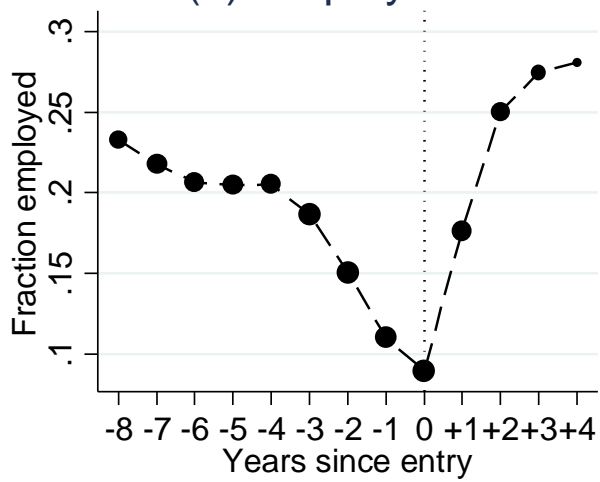

(d) Non taxable benefits

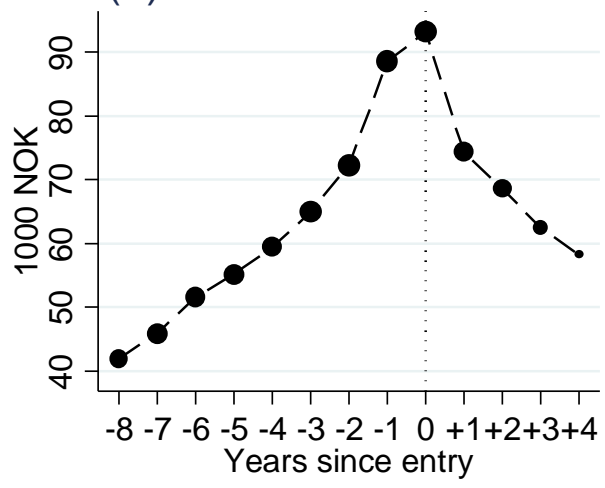

Figure 1. Annual employment, earnings, and benefit claims among QP participants.

Note: The graphs are based on all QP entrants 2008-2011 (19,211 persons); see also note to Table 1. The sizes of the dots are proportional to the number of observations behind each data point. Back-in-time-observations are censored at age 18.

\section{Methodology}

The research question we seek to answer is how participation in QP affects earnings, employment, and benefit trajectories for up to four years after the year of program entry; i.e., we will try to find out how much - if anything - of the patterns displayed in Figure 1 that can be interpreted as causal. Given the relatively long durations of QP participation, we expect the causal impacts to change significantly with time since program entry. A probable dynamic effect pattern is that there are negative (lock-in) effects during the first 1-2 years after entry, whereas the potentially favorable post-treatment effects build up gradually afterwards. The statistical models we use to evaluate the program portray a person $i$ who in some base-year $t$ 
belongs to a risk-group of potential QP entrants during the next four years $(t+1, \ldots, t+4)$ provided that QP becomes available in person i's municipality during this period. The model is then designed to explain various labor market outcomes over a period of up to four years after the first possible QP entry year (i.e., up to five years after the base-year). ${ }^{3}$

To define the potential risk-group; i.e., a group of persons who potentially could have participated in QP - we rely on the eligibility criteria set out in the legislation, and include all persons aged 18-55 who in a base-year $t$ received some kind of temporary income support (except sick-pay) from the welfare state, and at the same time had low previous labor earnings and thus low (or no) social insurance entitlements in the coming years. ${ }^{4}$ We use the term potential risk-group to emphasize that they are actually at risk only if the program becomes available in the municipality during the next four years.

The base-years used in our analysis are 2000-2007, with outcomes measured in 2001-2012. This implies that all the base-years are strictly prior to the first local implementation of the program, ensuring (by construction) that there is no QP-participation in the base-years. It also implies that the base-year observations recorded in the first part of our data window (20002003) are never exposed to the risk of actual QP participation in the period we follow them (since we consider the entry-risk to negligible after four years and since the first municipalities introduced the program in 2008), whereas subsequent base-year cohorts are exposed to an increasing extent. This pattern is illustrated in Table 2. For example, we see that the 2004 base-year cohort is exposed to QP risk in the fourth year $(t+4=2008)$ provided that they resided in a municipality implementing the reform in 2008. The only group exposed to QP risk in the first year after the base-year (i.e., in $t+1$ ) is the 2007-cohort in early reform municipalities. This is also the only group that can be followed for as much as four years after QP entry in our data.

\footnotetext{
${ }^{3}$ We disregard the risk of QP entry more than four years after the base-year. In principle, we could have modeled entry in a fifth year also, since outcomes are modeled up to five years after the base-year. But, as becomes clear when we explain our statistical approach, this would have complicated the model considerably without adding anything of substance (the probability of entering QP five years after the base-year is around 0.3 $\%)$.

${ }^{4}$ The included benefits are unemployment insurance, temporary disability insurance (not including sickpay, which is payable for a maximum of one year), and social assistance. In the main specification of our model, the definition of low previous labor earnings is that max(last years' earnings, average earnings last three years) does not exceed 170,000 NOK (measured in 2013-value). By comparison, the average fulltime-equivalent annual salary for all employees in Norway in 2013 is approximately 500,000).
} 
Table 2. Entry possibilities in four year period after base-year. By base-year and municipality reform year.

\begin{tabular}{|c|c|c|c|}
\hline & $\begin{array}{l}\text { Reform year } 2008 \\
\text { (55\% of population) }\end{array}$ & $\begin{array}{l}\text { Reform year } 2009 \\
\text { ( } 37 \% \text { of population) }\end{array}$ & $\begin{array}{l}\text { Reform year } 2010 \\
\text { (8\% of population) }\end{array}$ \\
\hline \multicolumn{4}{|l|}{ Base year: } \\
\hline 2000 & No entry possibility & No entry possibility & No entry possibility \\
\hline 2001 & No entry possibility & No entry possibility & No entry possibility \\
\hline 2002 & No entry possibility & No entry possibility & No entry possibility \\
\hline 2003 & No entry possibility & No entry possibility & No entry possibility \\
\hline 2004 & 2008 & No entry possibility & No entry possibility \\
\hline 2005 & 2008,2009 & 2009 & No entry possibility \\
\hline 2006 & $2008,2009,2010$ & 2009,2010 & 2010 \\
\hline 2007 & $2008,2009,2010,2011$ & $2009,2010,2011$ & 2010,2011 \\
\hline
\end{tabular}

To explain our empirical strategy in more detail, let $y_{i, t+r}$ be a labor market outcome in year $t+r$ for a base-year observation belonging to year $t$, and let $Q P_{i, t+r-p}$ be indicator variables equal to one for persons who entered the QP program $p$ years before the outcome year in question (and zero otherwise). Furthermore, let $\mathbf{x}_{\mathrm{it}}$ be a vector of observed individual characteristics measured in the base-year, including age (44 categories), sex, years of education (8 categories), immigrant status (3 categories), labor earnings (in the base-year and on average during the three years leading up to the base-year), social insurance benefits, social assistance, number of months with social assistance, number of months with UI claims, and number of months with temporary disability insurance benefits. In the absence of unobserved sorting (i.e., if we are willing to assume that participation is randomly assigned, conditional on observed characteristics), we can regress the various outcomes on a vector of program participation indicators; e.g.

$$
y_{i, t+r}=\mathbf{x}_{\mathrm{it}}^{\prime} \boldsymbol{\beta}+\alpha_{m \times \mathrm{x} \times r}+\sum_{p=0}^{r-1} \lambda_{p} Q P_{i, t+r-p}+u_{i, t+r}, \quad t=2000, \ldots, 2007, \quad r=1, \ldots, 5,
$$

where $\alpha_{m \times t \times r}$ is a fixed effect for all combinations of municipality $(m)$, base-year $(t)$ and years since base-year $(r)$ (with municipality assigned in the base-year) and $u_{i, t+r}$ is a residual. ${ }^{5}$ Here,

\footnotetext{
${ }^{5}$ We apply this very flexible specification of municipality-time effects throughout the paper, implying the use of 14,624 dummy variables. Note that this is more general than what we would get from more "standard" municipality-year dummies, since we allow the effects in a given municipality in a given calendar year to depend on time since base-year, i.e., the time since the condition of being dependent on temporary income support was imposed. The reason for this is that the composition of groups that vary with respect to the number of years since they were observed to be in need of temporary income support may be very different; hence they may also respond differently to, e.g., fluctuations in local labor market conditions.
} 
$\lambda_{0}$ represents the effect on the outcome of having entered the program in the same year, whereas, e.g., $\lambda_{3}$ represents the effects of having entered it three years ago; in both cases relative to not having entered the program at all.

Unfortunately, the assumption of conditional random assignment is unconvincing in this case. Participation in QP is likely to be highly selective even conditional on a wide range of observed characteristics. Given the character of the program (in particular its explicit targeting of individuals under high risk of becoming completely reliant on means-tested social assistance), we expect actual participants to be strongly negatively selected; hence, we cannot use the results from this regression to produce estimates with a causal interpretation. Redesigning (1) to include individual fixed effects and thus exploit the before-after treatment dimensions illustrated in Figure 1 for actual QP participants would also not solve the problem, since participants' earnings and employment profiles prior to entry have been anything but fixed, and since it is probable that QP participation is triggered by unobserved events and/or by changes in attitudes/motivation that would have broken pre-program outcome-trends even in the absence of QP.

Instead, we are going to rely on an instrumental variables approach, whereby we use the rollout of the program during 2008-2010, interacted with individual predicted participation propensities, as instruments. Intuitively, identification then relies on the observed relationship between QP participation propensities and economic performance before/after implementation of QP in each municipality. A disproportionally positive (negative) development for persons with high QP propensity after actual implementation of QP in their municipality will then be interpreted as indicative of a positive (negative) effect. This identification strategy requires that we control for "everything else" that could have induced spurious time trends or cross-sectional differences - in the relationship between outcomes and QP participation propensities. Hence, as we explain in more detail below, our approach is designed to isolate what we consider to be the reliably exogenous variation arising from the staggered QP introduction only.

A preparatory step in this empirical strategy is to construct the instruments for the four different entry alternatives that may become relevant $(1,2,3$, or 4 years after the base-year). We do this by estimating individual participation propensities as functions of observed explanatory variables on the basis of the set of baseline-observations for which there is a genuine risk of entering QP. As it turns out, the selection process into QP appears to have varied quite a lot 
over time and between municipalities with different reform implementation years (Schafft and Spjelkavik, 2011). Hence, we cannot simply estimate a single QP participation propensity. Instead, we estimate separate QP entry probabilities for each relevant combination of baseyear cohort, entry year, and reform-year. As shown in Table 2, this gives us 19 different entry probabilities to estimate. Let $z_{i, t, q, r}$ be an indicator variable equal to 1 if person $i$ observed in a base-year $t$ living in a municipality implementing QP in year $q$ entered the program $r$ years after the base-year, and let $\tilde{\mathbf{x}}_{\text {it }}$ be a vector of covariates constituting a restricted/reduced set of covariates. ${ }^{6}$ We then estimate the corresponding entry probabilities

$$
\hat{z}_{i, t, q, r}=f\left(\tilde{\mathbf{x}}_{\mathbf{i t}}^{\prime} \hat{\gamma}_{\mathbf{t}, q, \mathbf{r}}\right), \quad t=2004, \ldots, 2007, q=2008, \ldots, 2010, r=1, \ldots, 4,
$$

for all the (19) existing combinations of $t, q$, and $r$ in our data using binomial logit models. ${ }^{7}$ Now, although Equation (2) can be estimated on the subset of actual risk-groups only, the 19 resultant predictions can be attributed to all base-year observations in the dataset (since $\tilde{\mathbf{x}}_{\mathbf{i t}}$ is always observed). They can then be interpreted as predicted annual hypothetical entry probabilities had the respective combinations of $t, q$, and $r$ become relevant for $i$. For further use, we stack them in a $(19 \times 1)$ vector denoted $\hat{\mathbf{z}}_{i t}$.

Turning back to Equation (1), we note that what we need in order to instrument the endogenous variables $Q P_{i, t+r-p}$ is predicted actual QP entry probabilities for the $0-4$ years prior to the outcome year in question. For each outcome year $t+r$, we construct these such that they represent the actually corresponding $\hat{z}_{i, t, q, r}$ if the program actually was available for the $(t, q, r)$ combination in question, and zero otherwise. Doing this, we end up with five instruments representing actual entry probabilities relative to the outcome year, which we denote $\mathbf{z}_{i t}^{*}=\left[\begin{array}{lllll}z_{i, t+r}^{*} & z_{i, t+r-1}^{*} & z_{i, t+r-2}^{*} & z_{i, t+r-3}^{*} & z_{i, t+r-4}^{*}\end{array}\right]$. An example may be clarifying: Consider a person with base year $t=2007$ who was resident in a municipality implementing the program in $q=2008$. Examining a corresponding outcome in $2008(2007+1)$, the predicted probability of

\footnotetext{
${ }^{6}$ The variable $\tilde{\mathbf{x}}_{\mathrm{it}}$ in Equation (2) contains the same variables as $\mathbf{x}_{\mathrm{it}}$ in Equation (1), but with scalar variables instead of indicator variables. The reason for this is that we need a more restrictive specification in this case to avoid problems with no variation in QP entry for particular values of covariates. The following variables are included in $\tilde{\mathbf{x}}_{\mathrm{it}}$ : Age, sex, education level, immigrant status, earnings in the base-year, max of earnings in the base-year and in the last three years leading up to the base-year, taxable benefits in the base-year, non-taxable benefits in the base-year, number of months with social assistance in the base-year, number of months with UI benefits in the base-year, and number of months with temporary disability benefits in the base-year.

${ }^{7}$ We have also tried out linear probability and probit models, with only minor changes in the results.
} 
having entered in the same year is given as $z_{i, 2007+1}^{*}=\hat{z}_{i, 2007,2008,1}$, whereas the predicted probabilities of having entered in previous years $\left(z_{i, 2007+1-1,}^{*} z_{i, 2007+1-2,}^{*} z_{i, 207+1-3}^{*} z_{i, 2007+1-4,}^{*}\right)$ are all equal to zero, since the program did not exist at these points in time. Examining the same person's outcome in $2009(2007+2)$, we have that the probability of entering in the same year is given by $z_{i, 2007+2}^{*}=\hat{z}_{i, 2007,2008,2}$, whereas the probability of having entered last year is $z_{i, 2007+2-1}^{*}=\hat{z}_{i, 2007,2008,1}$, and the probabilities corresponding to earlier entries are again zero. Note that $z_{i, 2007+1}^{*}=z_{i, 2007+2-1}^{*}=z_{i, 2007+3-2}^{*}=z_{i, 2007+4-3}^{*}=z_{i, 2007+5-4}^{*}$, since they all refer to entry in the same calendar year.

Now, given the way we have constructed the five elements in $\mathbf{z}_{i t}^{*}$, we could have substituted these predictions directly for the QP participation indicators in Equation (1). However, we would then not end up with a correct 2SLS model, since there are a significant number of actual QP entries that are recorded in municipalities and/or years for which the program does not exist. The most likely explanation for this is that there are errors in municipalityassignment or that persons have migrated to another municipality after the base-year. This represents a potential source of contamination bias (the non-participant group is contaminated with a number of participants), which unaccounted for will bias estimated effects toward zero. To avoid this problem, we use the predictions in $\mathbf{z}_{i t}^{*}$ as instruments for all observed entry decisions instead. A further complication is that there are not one, but four mutually exclusive endogenous variables in (1) - namely QP entry in the first, second, third, and fourth year after the base-line year. Although there is a single element in $\mathbf{z}_{i t}^{*}$ that corresponds directly to each of these endogenous variables, we include all four elements as instruments for all four endogenous variables. Markussen and Røed (2014) have shown that if there are "cross-effects" implying that each instrument has effects on more than one of the endogenous variables, failure to account for these cross-effects may yield biased results. ${ }^{8}$ Hence our first- and second step linear equations become

$$
\begin{aligned}
Q P_{i, t+r-p} & =\mathbf{x}_{\mathbf{i t}}^{\prime} \boldsymbol{\beta}^{q p}+\alpha_{m \times x \times r}^{q p}+\mathbf{z}_{i t}^{*}{ }^{p} \boldsymbol{\sigma}^{p}+\mathbf{d}_{\mathbf{t} \times r}^{\prime} \mathbf{z}_{\mathbf{i t}} \boldsymbol{\tau}^{q p}+\mathbf{d}_{\mathbf{q}}^{\prime} \mathbf{z}_{\mathbf{i t}} \boldsymbol{\rho}^{p}+\zeta_{i, t+r-p}, \\
y_{i, t+r} & =\mathbf{x}_{\mathbf{i t}}^{\prime} \boldsymbol{\beta}+\alpha_{m \times x \times r}+\sum_{p=0}^{r-1}\left(\lambda_{p} \widehat{Q P_{i, t+r-p}}\right)+\mathbf{d}_{\mathbf{t} \times \mathbf{r}}^{\prime} \mathbf{z}_{\mathbf{i t}} \boldsymbol{\tau}+\mathbf{d}_{\mathbf{q}}^{\prime} \mathbf{z}_{\mathbf{i t}} \boldsymbol{\rho}+\varepsilon_{i, t+r},
\end{aligned}
$$

\footnotetext{
${ }^{8}$ In our case, the results are almost exactly the same regardless of whether we allow all instruments to affect all endogenous variables or not. As expected, we also get similar, but somewhat smaller effect estimates if we use $\mathbf{z}_{i t}^{*}$ directly as the first-step predictions.
} 
for $t=2000, \ldots, 2007, r=1, \ldots, 5$, and $p=0, \ldots 4$, where $\mathbf{d}_{\mathbf{t} \times \mathbf{r}}$ is a vector of base-year-outcome-year dummy variables (one dummy for each possible combination of base-year and outcome-year), $\mathbf{d}_{\mathbf{q}}$ is a vector of reform-year dummy variables (time constant, but varying across municipalities with different reform implementation years), and $\widehat{Q P_{i, t+r-p}}$ are the OLS predictions from (3). Our interest is in the coefficients $\lambda_{p}$, which represents the effects of having entered QP the same year $(p=0)$, the last year $(p=1)$, and so forth, in all cases relative to nonparticipation.

The rationale behind including the control variables $\left\{\mathbf{d}_{\mathbf{t} \times \mathbf{r}}^{\prime} \mathbf{z}_{\mathbf{i t}}, \mathbf{d}_{\mathbf{q}}^{\prime} \mathbf{z}_{\mathbf{i t}}\right\}$ in the statistical model, in addition to those already included in (1), is as follows:

- $\mathbf{d}_{\mathbf{t} \times \mathbf{r}}^{\prime} \mathbf{z}_{\mathrm{it}}(8$ base-years $\times 5$ outcome years $\times 19$ hypothetical entry probabilities $=760$ variables) is included to control for any differences in the outcomes and their timedevelopments that correlate systematically with the QP participation propensities. ${ }^{9}$

- $\quad \mathbf{d}_{\mathbf{q}}^{\prime} \mathbf{z}_{\text {it }}$ (3 QP-implementation years $\times 19$ hypothetical entry probabilities $=57$ variables $)$ is included to control for any differences in the correlation between QP propensities and outcomes between municipalities that implemented the reform at different times.

Hence, by including these controls, we narrow down the variation in participation propensities used to identify the causal effects to the desired quasi-experimental part of it.

Since the instruments used to identify the causal effects of program participation incorporate the phasing-in of the program itself, all actual participants have obviously been directly induced to participate by the instruments. In the terminology used by Angrist et al. (1996), all actual participants are “compliers”, and there exists no “always-takers” or “defiers”. Provided that QP influences the clients' outcomes through actual participation in the program only, our statistical approach thus identifies the average treatment effects among the treated (ATET). This assumption will be violated if, for example, case workers punish claimants who refuse to participate in QP (despite that this is not how QP is supposed to be used; see Section 2), or if welfare-recipients reduce efforts to find work in anticipation of QP participation. Note, however, that if such side-effects are empirically relevant, our estimates are still valid as measures of overall impacts of the program measured relative to the number of actual participants, since

\footnotetext{
${ }^{9}$ When participation propensities are estimated by linear probability models, we impose one reference (zero-restriction) for each of the 19 entry routes to avoid perfect colinearity with $\mathbf{x}_{\mathrm{it}}$.
} 
these side-effects also represent causal impacts of being exposed to the program. They can no longer be interpreted as ATET, however. Yet, from a policy perspective, it is probably the program's overall impacts on the target group's subsequent economic performance, relative to the program's overall costs (as determined by the number of actual participants), that is the parameter of main interest - regardless of how the individual effects are distributed between actual and potential participants. And that is exactly what comes out of our IV approach.

Our empirical strategy hinges on the assumption that the unobserved composition of the baseyear risk populations was not affected by whether the reform was implemented in 2008, 2009, or 2010. This assumption could have been violated if, for example, would-be QP participants migrated to the municipalities with early introduction in order to take advantage of the program. Since the last base-year used in our analysis is 2007, and the first municipalities implemented the program in 2008, this does not appear very likely; though not entirely impossible. The decision to implement QP was taken by the Norwegian Parliament in June 2007, giving well-informed agents the possibility to move to an early-implementing municipality during July-December 2007. We can check whether or not such migrations have influenced our estimates by tying persons to the address they had a year before the base-year. We return to this issue in Section 5 after having presented our main results. Note, however, that endogenous migrations after the base year (as discussed above) do not invalidate our empirical approach, since we use initial residency as the basis for our instruments. It makes our instruments weaker, however.

A final point to note is that, as we show in the next section, many of the individuals in our dataset qualify for being included in the risk-group in more than one base-year. Given the way we construct the analysis data, these persons will contribute with multiple - and sometimes overlapping - five-year outcome sequences. We have done this to ensure a completely symmetric risk-group composition throughout the data window. We take the multiplicity of observations into account when we compute standard errors, however, by considering all observations from the same person as a cluster.

\section{The analysis population}

In this section, we give a brief description of the analysis population used in the statistical analysis. Given the rather vague eligibility criteria, it is not a trivial exercise to identify the population at risk of entering QP during a forthcoming four-year period. The formal rules 
described in Section 2 target persons with substantially reduced labor income capacity and no or very limited social insurance entitlements. In principle, this implies that everyone who have had low labor earnings over some time and also received some kind of temporary income support from the welfare state may become eligible. Since social insurance entitlements in Norway generally depend on the maximum of labor earnings taken over the last calendar year and the average over the last three years, we also base our definition of "low labor earnings" on this maximum. In our main specification, we set the threshold to 170,000 NOK $(28,000 \$)$ (measured in 2013 value). This is roughly one third of the average full-time-full-year earnings level in Norway. A price we pay for excluding persons above this relatively low earningsthreshold is that a number of actual participants fall outside the risk-group and are therefore left out of the analysis. In a robustness analysis, we thus increase the earnings-requirement to 340,000. This raises the overall sample size by $65 \%$ and the number of actual participants covered by $11 \%$. Note that we do not exclude persons from the dataset on the basis of the level of temporary social insurance benefits in the base-year (even though no/low benefit entitlement is among the eligibility criteria), since - given our requirement of low earnings the last three years - these benefits are likely to become exhausted in the near future.

Table 3. Descriptive statistics analysis population

\begin{tabular}{lcc} 
& & Non-participants \\
\cline { 2 - 3 } Number of base-year observations & 21,082 & $1,386,310$ \\
Number of individuals & 8,896 & 307,003 \\
Mean age & 32.5 & 36.7 \\
Women \% & 61.0 & 46.8 \\
Non-native \% & 36.2 & 15.3 \\
High school \% & 17.8 & 35.8 \\
College/University \% & 6.1 & 10.8 \\
Mean labor earnings base-year (1000NOK, 2013) & 19.5 & 28.8 \\
Mean social assistance base-year (1000NOK, 2013) & 103.4 & 54.4 \\
Mean taxable benefits (1000NOK, 2013) & 50.8 & 135.4 \\
\hline
\end{tabular}

Note: Averages and fractions are computed over base-year observations. $1000 \mathrm{NOK}=167$ \$ (based on exchange rate April 2014)

Table 3 shows some descriptive statistics for the sample used in the main part of the analysis. There are 315,899 individuals included, out of which 8,896 (2.8 \%) actually participated in QP. The participants tend to be quite different from the non-participants, e.g., in the form of lower labor earnings and taxable social insurance benefits, higher levels of social assistance, and lower levels of education. Women and immigrants are significantly overrepresented in the participant group. 
On average, each individual contributes 4.5 baseline-year observations, and thus $5 \times 4.5=22.5$ (partly overlapping) outcome-year observations. A point to note is that our statistical analysis only includes roughly half of the 19,211 QP participants described in Section 2 above. The main reason for this is that to ensure a completely symmetric composition of analysis populations in municipalities with different QP implementation dates, our risk groups are defined on the basis of individual characteristics strictly prior to program implementation; i.e., no later than 2007. As a result, we lose persons who entered the risk group for the first time during 2008-2011, and this alone accounts for $62 \%$ of the overall loss of actual participants in the analysis data. In addition, our definition of the risk population is imperfect, implying that some persons enter QP even though they were not considered (by us) to be at risk; i.e., they had too high income in the base-year, were too old, or did not receive the types of temporary income support that we have used to define the risk population. The latter is particularly relevant for humanitarian immigrants who sometimes enter the program directly without first receiving the temporary transfers. As a result, the participant group included in our statistical analysis deviates somewhat from the group of all participants described in Table 1. In particular, we oversample female and undersample immigrant participants.

\section{Results}

We start out this section by summarizing the computation of the instruments and the results from the first-step equations. We thereafter turn to the estimated effects of actual participation.

\subsection{Explaining QP participation: The instruments and the first-step equations}

Given that we estimate as much as 19 different participation models based on Equation (2) (depending on base-year, the number of years that have passed since the base year, and the timing of the reform in the municipality of residence) and the relatively large number of explanatory variables included in each model, we do not present these results in any detail. Instead, to illustrate the identified participation patterns, we compute the average of the 19 probability-predictions for each individual base-year observation, and show how the distributions of the resultant participation propensity summary statistics vary between participants and non-participants, and how they correlate with the most important observed characteristics used in the estimation process. As it turns out, the average estimated annual QP entry probabilities (taken over the 19 possible entry-routes) are low for virtually everyone; $3.5 \%$ for participants and $1.2 \%$ for non-participants. Over a four-year risk period, this implies that actual 
participants according to our model had a participation probability around $13.3 \%$, whereas non-participants had a participation probability around $4.7 \%$. The relatively low participation probabilities estimated even for participants reflects that it is difficult to identify a genuine high-risk groups based on observed characteristics only, and thus highlights the magnitude of the selection problem. Nevertheless, observed characteristic are associated with significant differences in participation propensities. This is illustrated in Figure 2, where we plot the cumulative distribution functions for the predicted participation propensities separately for participants and non-participants.

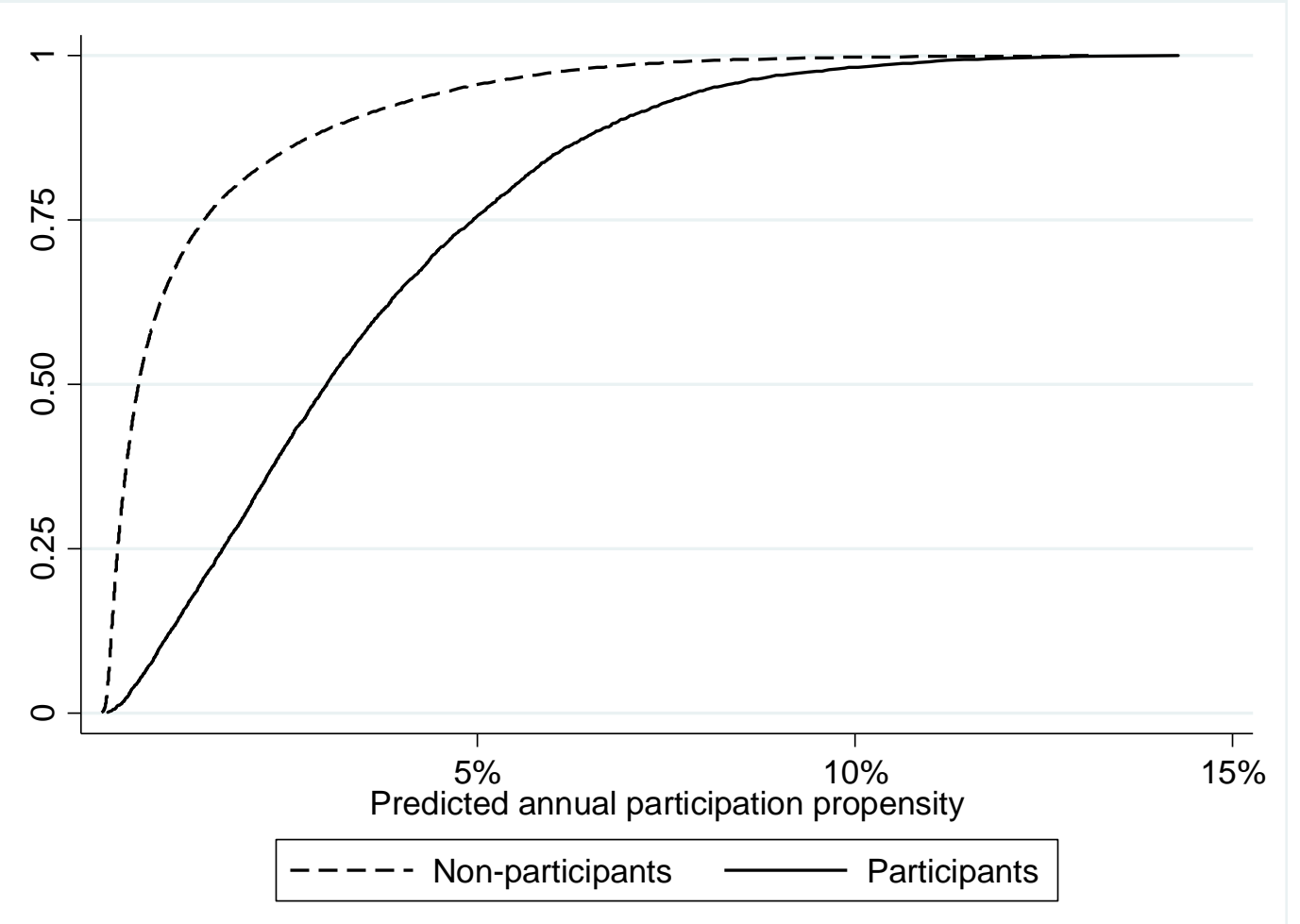

Figure 2. The cumulative distribution of predicted average annual QP participation probabilities

Note: The distribution functions are based on the averages of the 19 hypothetical QP propensities predicted from Equation (2).

Figure 3 further illustrates important aspects of the sorting process by plotting the mean values of various observed characteristics by percentile in the distribution of average QP participation probabilities. Those with the highest participation probabilities are young immigrants with almost zero labor earnings and little schooling, who have virtually no access to (taxable) social insurance transfers, and relatively large amounts of means-tested social assistance. At the other end, those with the lowest participation probabilities are older natives, with some previous labor earnings and schooling, significant social insurance transfers, but virtually no means-tested social assistance. 
(a) Age

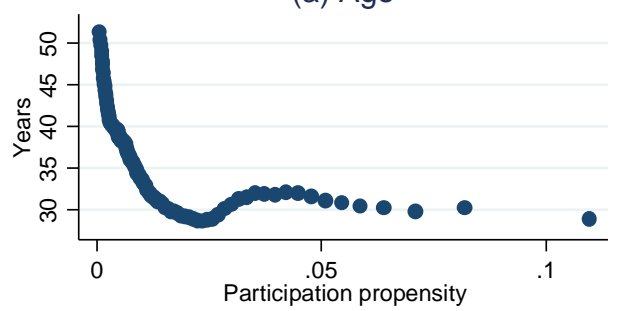

(c) Labor earnings

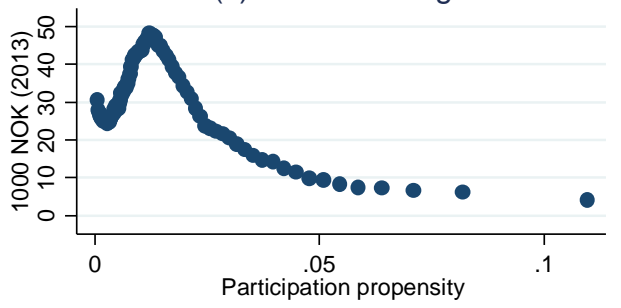

(e) Taxable benefits

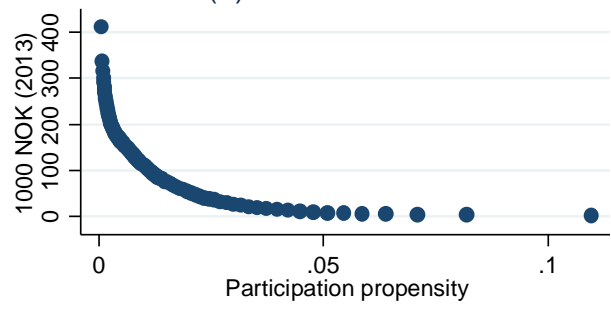

(b) Non-native

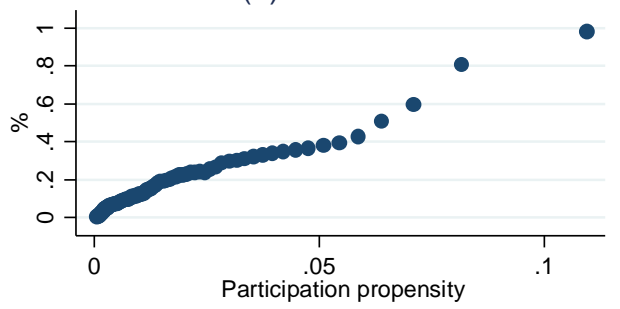

(d) Years of schooling

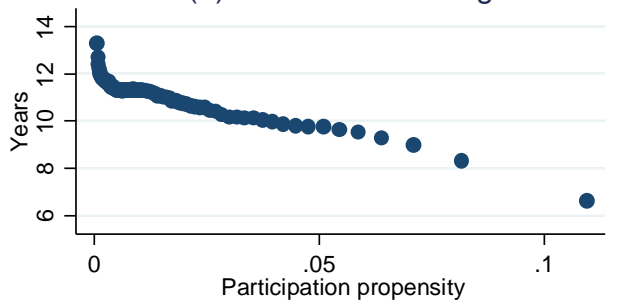

(f) Non-taxable benefits

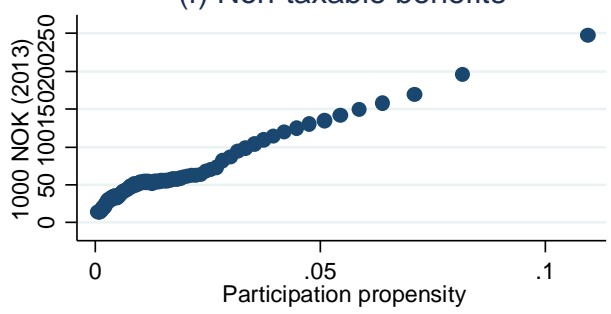

Figure 3. Mean values of selected individual characteristics by percentile in the distribution of average predicted QP participation propensity.

Note: QP participation propensity is computed as the average of the 19 hypothetical QP propensities predicted from Equation (2).

Table 4 presents the estimation results from the first stage (Equation (3)). Unsurprisingly, we find strong effects of predicted participation on actual participation. Note, however that the diagonal elements of Table 4 are not equal to one, nor are the off-diagonal elements always equal to zero. These patterns primarily reflect that participation sometimes occur in municipalities/years that were not considered to be at risk when the instrument was constructed. Moreover, while the instruments are constructed as a non-linear function of individual characteristics, they enter linearly in the IV model. 
Table 4. First stage estimates (Eq. 3), based on sample with low earnings threshold. Effects of excluded instruments on entry probabilities in year $t+r-p$ for $p=0,1,2,3,4$ (standard errors in parentheses)

\begin{tabular}{|c|c|c|c|c|c|}
\hline & $Q P_{i, t+r-0}$ & $Q P_{i, t+r-1}$ & $Q P_{i, t+r-2}$ & $Q P_{i, t+r-3}$ & $Q P_{i, t+r-4}$ \\
\hline$z_{i, t+r-0}^{*}$ & $\begin{array}{c}0.740^{* * *} \\
(0.025)\end{array}$ & $\begin{array}{l}-0.015 \\
(0.012)\end{array}$ & $\begin{array}{l}-0.002 \\
(0.006)\end{array}$ & $\begin{array}{l}-0.004 \\
(0.003)\end{array}$ & $\begin{array}{c}0.002 \\
(0.001)\end{array}$ \\
\hline$z_{i, t+r-1}^{*}$ & $\begin{array}{c}0.011 \\
(0.030)\end{array}$ & $\begin{array}{c}0.740 * * * \\
(0.026)\end{array}$ & $\begin{array}{l}-0.014 \\
(0.013)\end{array}$ & $\begin{array}{c}0.002 \\
(0.007)\end{array}$ & $\begin{array}{c}-0.006^{* *} \\
(0.003)\end{array}$ \\
\hline$Z_{i, t+r-2}^{*}$ & $\begin{array}{c}-0.056^{* *} \\
(0.027)\end{array}$ & $\begin{array}{c}0.009 \\
(0.036)\end{array}$ & $\begin{array}{c}0.741^{* * *} \\
(0.028)\end{array}$ & $\begin{array}{l}-0.013 \\
(0.014)\end{array}$ & $\begin{array}{l}0.010^{*} \\
(0.006)\end{array}$ \\
\hline$z_{i, t+r-3}^{*}$ & $\begin{array}{c}0.020 \\
(0.023)\end{array}$ & $\begin{array}{c}-0.074^{* *} \\
(0.038)\end{array}$ & $\begin{array}{c}0.014 \\
(0.040)\end{array}$ & $\begin{array}{c}0.752 * * * \\
(0.030)\end{array}$ & $\begin{array}{c}-0.023^{* *} \\
(0.011)\end{array}$ \\
\hline$Z_{i, t+r-4}^{*}$ & $\begin{array}{c}-0.031^{*} \\
(0.018)\end{array}$ & $\begin{array}{c}0.023 \\
(0.038)\end{array}$ & $\begin{array}{c}-0.075 \\
(0.046)\end{array}$ & $\begin{array}{c}0.037 \\
(0.047)\end{array}$ & $\begin{array}{c}0.796 * * * \\
(0.035)\end{array}$ \\
\hline $\begin{array}{l}\text { F-statistic excluded } \\
\text { instruments }\end{array}$ & 15.82 & 15.82 & 18.69 & 21.95 & 25.21 \\
\hline
\end{tabular}

Note: Standard errors are clustered at individuals. $\left.{ }^{* * *}\right)(* * *)$ indicate significance at the 10(5)(1) percent levels. Number of observations: 7,036,980.

Control variables: Municipality×base-year×years-since-base-year-fixed effects (18,280 dummy variables), age (44 dummy variables), sex, education (8 dummy variables), immigrant status (3 dummy variables), labor earnings (in the base-year and as average over the three years leading up to the base-year), taxable benefits in the base-year, non-taxable benefits in the base-year, number of months with social assistance in the base-year, number of months with UI benefits in base-year, number of months with temporary disability benefits in base-year, estimated QP participation propensities interacted with base-year×outcome-year (760 variables), and estimated QP participation propensities interacted with reform-year in the municipality (57 variables).

\subsection{The causal effects of QP participation: The second-step equations}

We are interested in the effects of QP participation on a number of outcomes. Since the main aim of the program is to help persons into regular employment, we focus on employment as the main success criterion. For each year, employment is defined as having labor-related earnings (from unsubsidized work) above certain thresholds, which we set relatively low given the program's target group of hard-to-employ persons. In addition, we use outcomes measuring the level of earnings as well as the level of various types of welfare state transfers. For the latter outcomes, we of course have considerable a priori knowledge about the true causal effects of the QP program, since the program by design offers a taxable full-year-equivalent transfer of 170,000 NOK $(28,000 \$)$, which to some extent substitutes for non-taxable benefits (means-tested social assistance). This implies that we can use the models' estimated effects on these outcomes as a sort of plausibility-test.

We present our main results regarding employment and earnings in Table 5. For comparison, we present the results from our preferred IV specification (based on Equation (4)) together with the "naïve" OLS-estimates (based on Equation 1). While the OLS estimates consistently indicate adverse effects of QP in the form of lower employment and lower earnings, the IVestimates indicate favorable effects from 2-3 years after entry. In particular, QP participation seems to raise the chances of obtaining at least some employment quite significantly. Based 
on the widest employment definition (annual earnings exceeding at least 85,000 NOK), the point estimates indicate a 10 percentage point increase in the employment probability two years after QP entry, a 14 point increase after three years, and an 18 point increase after four years (Column II). The estimated impacts on the levels of annual earnings follow a similar time pattern (Column IV); after four years, QP participation is predicted to raise annual earnings by around 50,000 NOK (8,300 \$). Given that the average fulltime-equivalent annual earnings level in Norway is around 500,000 NOK, this is in quantitative terms not a huge effect. However, the linear earnings equation is poorly designed to capture the true earnings effects of QP, since the effects are likely to be concentrated in the extreme lower tail of the earnings distribution. Using a log-specification instead (Column XII), we estimate a QP impact of 1.4 log-points after four years, indicating that those who actually participate in the program (and typically have very poor earnings prospects) experience large relative increases as a result of QP participation.

Although the statistical uncertainty associated with all the employment and earnings estimates is relatively large when evaluated one by one, it is notable that the overall pattern of estimated coefficients conveys a coherent and plausible story: QP participation reduces employment and labor earnings slightly during the first 1-2 years of participation and raises them afterwards. At the same time it sharply (and statistically significantly) increases the level of taxable benefits (Column VIII) and reduces the level of social assistance (Column X). The sizes of the latter effect-estimates correspond closely to what we would expect on the basis of prior knowledge. For example, the estimated rise in taxable benefits of 106,000 NOK in the first year after QP entry accords well with the fact that annual full-year benefits are equal to 170,000 NOK, as some QP entrants would have been eligible for small amounts of taxable benefits even without the program and as some entrants do not participate the whole year.

As pointed out in Section 3, provided that QP affects actual participants only, our effect estimates can be interpreted as the estimated average treatment effect among the treated (ATET). If there are indirect effects on non-participants, e.g., in the form of "threat effects" or in the form of changes in the local treatment culture that spill over to other social assistance recipients, our IV estimates are still valid as measures of the overall effects relative to the number of treated. But, since they attribute all (reduced form) effects to the actual participants they will in this case underestimate the number of affected clients and thus overestimate the causal effect for each of them. 
Table 5. Main estimation results (Eq. 4) for sample with low earnings threshold. Ordinary Least Squares and Instrumental Variables (clustered standard errors in parentheses)

\begin{tabular}{|c|c|c|c|c|c|c|c|c|c|c|c|c|}
\hline & \multicolumn{2}{|c|}{$\begin{array}{c}\text { Employment } \\
(85,000 \text { NOK thresh- } \\
\text { old })\end{array}$} & \multicolumn{2}{|c|}{$\begin{array}{c}\text { Employment } \\
(170,000 \text { NOK thresh- } \\
\text { old })\end{array}$} & \multicolumn{2}{|c|}{$\begin{array}{c}\text { Labor earnings (1000 } \\
\text { NOK, 2013-value) }\end{array}$} & \multicolumn{2}{|c|}{$\begin{array}{c}\text { Taxable benefits } \\
\text { (1000 NOK, 2013- } \\
\text { value) }\end{array}$} & \multicolumn{2}{|c|}{$\begin{array}{c}\text { Non-taxable benefits } \\
\text { (1000 NOK, } 2013 \\
\text { value) }\end{array}$} & \multicolumn{2}{|c|}{$\begin{array}{c}\text { Log labor earnings } \\
(\log (\text { earnings }+1)) \\
(1000 \text { NOK, } 2013 \text { value })\end{array}$} \\
\hline & I & II & III & IV & $\mathrm{V}$ & VI & VII & VIII & IX & $\mathrm{X}$ & XI & XII \\
\hline & $\begin{array}{l}\text { Eq. } 1 \\
\text { (OLS) }\end{array}$ & $\begin{array}{l}\text { Eq. } 4 \\
\text { (IV) }\end{array}$ & $\begin{array}{l}\text { Eq. } 1 \\
\text { (OLS) }\end{array}$ & $\begin{array}{l}\text { Eq. } 4 \\
\text { (IV) }\end{array}$ & $\begin{array}{l}\text { Eq. } 1 \\
\text { (OLS) }\end{array}$ & $\begin{array}{l}\text { Eq. } 4 \\
\text { (IV) }\end{array}$ & $\begin{array}{l}\text { Eq. } 1 \\
\text { (OLS) }\end{array}$ & $\begin{array}{l}\text { Eq. } 4 \\
\text { (IV) }\end{array}$ & $\begin{array}{l}\text { Eq. } 1 \\
\text { (OLS) }\end{array}$ & $\begin{array}{l}\text { Eq. } 4 \\
\text { (IV) }\end{array}$ & $\begin{array}{l}\text { Eq. } 1 \\
\text { (OLS) }\end{array}$ & $\begin{array}{l}\text { Eq. } 4 \\
\text { (IV) }\end{array}$ \\
\hline \multicolumn{13}{|l|}{ Effects of QP } \\
\hline Same year $(p=0)$ & $\begin{array}{c}-0.201 * * * \\
(0.003)\end{array}$ & $\begin{array}{l}-0.086 \\
(0.074)\end{array}$ & $\begin{array}{c}-0.177 * * * \\
(0.002)\end{array}$ & $\begin{array}{l}-0.047 \\
(0.065)\end{array}$ & $\begin{array}{c}-60.02 * * * \\
(0.66)\end{array}$ & $\begin{array}{l}-26.33 \\
(21.40)\end{array}$ & $\begin{array}{c}12.70 * * * \\
(0.68)\end{array}$ & $\begin{array}{c}43.50 * * * \\
(15.66)\end{array}$ & $\begin{array}{l}45.18^{* * *} \\
(0.68)\end{array}$ & $\begin{array}{l}-27.00 * \\
(13.92)\end{array}$ & $\begin{array}{c}-0.829 * * * \\
(0.019)\end{array}$ & $\begin{array}{l}-0.133 \\
(0.396)\end{array}$ \\
\hline $\begin{array}{l}\text { First year after } \\
\text { entry }(p=1)\end{array}$ & $\begin{array}{c}-0.145^{* * *} \\
(0.004)\end{array}$ & $\begin{array}{c}0.010 \\
(0.064)\end{array}$ & $\begin{array}{c}-0.128 * * * \\
(0.003)\end{array}$ & $\begin{array}{l}-0.061 \\
(0.058)\end{array}$ & $\begin{array}{l}-47.00 * * * \\
\quad(0.88)\end{array}$ & $\begin{array}{l}-28.18 \\
(19.11)\end{array}$ & $\begin{array}{l}55.41^{* * *} \\
(0.83)\end{array}$ & $\begin{array}{c}106.50 * * * \\
(17.86)\end{array}$ & $\begin{array}{l}21.57 * * * \\
(0.72)\end{array}$ & $\begin{array}{c}-88.12 * * * \\
(13.33)\end{array}$ & $\begin{array}{c}-0.735^{* * *} \\
(0.021)\end{array}$ & $\begin{array}{l}-0.267 \\
(0.330)\end{array}$ \\
\hline $\begin{array}{l}\text { Second year } \\
\text { after entry }(p=2)\end{array}$ & $\begin{array}{c}-0.075^{* * *} \\
(0.005)\end{array}$ & $\begin{array}{c}0.096 \\
(0.079)\end{array}$ & $\begin{array}{c}-0.071 * * * \\
(0.004)\end{array}$ & $\begin{array}{c}0.028 \\
(0.071)\end{array}$ & $\begin{array}{l}-28.35^{* * *} \\
\quad(1.20)\end{array}$ & $\begin{array}{c}4.25 \\
(24.37)\end{array}$ & $\begin{array}{c}30.01^{* * *} \\
(1.05)\end{array}$ & $\begin{array}{l}-10.92 \\
(19.25)\end{array}$ & $\begin{array}{c}11.59 * * * \\
(0.81)\end{array}$ & $\begin{array}{l}-16.01 \\
(17.02)\end{array}$ & $\begin{array}{c}-0.448^{* * *} \\
(0.026)\end{array}$ & $\begin{array}{c}0.304 \\
(0.431)\end{array}$ \\
\hline $\begin{array}{l}\text { Third year after } \\
\text { entry }(p=3)\end{array}$ & $\begin{array}{c}-0.042^{* * * *} \\
(0.006)\end{array}$ & $\begin{array}{l}0.143 * \\
(0.082)\end{array}$ & $\begin{array}{c}-0.034^{* * *} \\
(0.005)\end{array}$ & $\begin{array}{c}0.081 \\
(0.073)\end{array}$ & $\begin{array}{c}-15.34 * * * \\
(1.64)\end{array}$ & $\begin{array}{c}12.18 \\
(24.96)\end{array}$ & $\begin{array}{c}19.86^{* * *} \\
(1.31)\end{array}$ & $\begin{array}{l}-25.23 \\
(20.93)\end{array}$ & $\begin{array}{c}0.54 \\
(0.94)\end{array}$ & $\begin{array}{c}-45.84 * * * \\
(16.09)\end{array}$ & $\begin{array}{c}-0.261 * * * \\
(0.033)\end{array}$ & $\begin{array}{c}0.465 \\
(0.434)\end{array}$ \\
\hline $\begin{array}{l}\text { Fourth year } \\
\text { after entry }(p=4)\end{array}$ & $\begin{array}{c}-0.012 \\
(-0.010)\end{array}$ & $\begin{array}{c}0.182 * * \\
(0.089)\end{array}$ & $\begin{array}{l}-0.008 \\
(0.009)\end{array}$ & $\begin{array}{c}0.121 \\
(0.079)\end{array}$ & $\begin{array}{c}-5.80 * * \\
(2.72)\end{array}$ & $\begin{array}{l}50.54^{*} \\
(26.71)\end{array}$ & $\begin{array}{c}23.53 * * * \\
(2.12)\end{array}$ & $\begin{array}{l}-32.08 \\
(22.10)\end{array}$ & $\begin{array}{c}-8.23 * * * \\
(1.58)\end{array}$ & $\begin{array}{c}6.73 \\
(16.90)\end{array}$ & $\begin{array}{l}-0.096 * \\
(0.053)\end{array}$ & $\begin{array}{c}1.395 * * * \\
(0.477)\end{array}$ \\
\hline
\end{tabular}

Note: Standard errors are clustered at individuals. ${ }^{* * *}\left({ }^{* * *}\right)$ indicate significance at the 10(5)(1) percent levels.

Number of observations in all models: 7,036,980. $1000 \mathrm{NOK}=167$ \$ (based on exchange rate April 2014).

Control variables included in all models: Municipality×base-year×years-since-base-year-fixed effects (18,280 dummy variables), age (44 dummy variables), sex, education (8

dummy variables), immigrant status (3 dummy variables), labor earnings (in the base-year and as average over the three years leading up to the base-year), taxable benefits in the base-year, non-taxable benefits in the base-year, number of months with social assistance in the base-year, number of months with UI benefits in base-year, and number of months with temporary disability benefits in base-year.

Additional control variables in IV-models: Estimated QP participation propensities interacted with base-year×outcome-year (760 variables), and estimated QP participation propensities interacted with reform-year in the municipality (57 variables). 
Table 6. Estimation results for sample with high earnings threshold. Instrumental Variables estimates (Eq. 4) (clustered standard errors in parentheses)

\begin{tabular}{|c|c|c|c|c|c|c|c|c|c|}
\hline & \multicolumn{3}{|c|}{ Whole population } & \multicolumn{3}{|c|}{ Natives only } & \multicolumn{3}{|c|}{ Immigrants only } \\
\hline & I & II & III & IV & $\mathrm{V}$ & VI & VII & VIII & IX \\
\hline & $\begin{array}{c}\text { Employment } \\
(>85,000 \\
\text { NOK })\end{array}$ & $\begin{array}{c}\text { Employment } \\
(>170,000 \\
\text { NOK })\end{array}$ & $\begin{array}{c}\text { Log labor } \\
\text { earnings }\end{array}$ & $\begin{array}{c}\text { Employment } \\
(>85,000 \\
\text { NOK })\end{array}$ & $\begin{array}{c}\text { Employment } \\
(>170,000 \\
\text { NOK })\end{array}$ & $\begin{array}{l}\text { Log labor } \\
\text { earnings }\end{array}$ & $\begin{array}{c}\text { Employment } \\
(>85,000 \\
\text { NOK })\end{array}$ & $\begin{array}{c}\text { Employment } \\
(>170,000 \\
\text { NOK })\end{array}$ & $\begin{array}{c}\text { Log labor } \\
\text { earnings }\end{array}$ \\
\hline \multicolumn{10}{|l|}{ Effects of QP } \\
\hline Same year $(p=0)$ & $\begin{array}{l}-0.043 \\
(0.069)\end{array}$ & $\begin{array}{c}0.017 \\
(0.062)\end{array}$ & $\begin{array}{c}0.055 \\
(0.372)\end{array}$ & $\begin{array}{l}-0.054 \\
(0.079)\end{array}$ & $\begin{array}{l}-0.023 \\
(0.069)\end{array}$ & $\begin{array}{c}0.210 \\
(0.471)\end{array}$ & $\begin{array}{c}0.017 \\
(0.118)\end{array}$ & $\begin{array}{c}0.080 \\
(0.110)\end{array}$ & $\begin{array}{c}0.193 \\
(0.624)\end{array}$ \\
\hline $\begin{array}{l}\text { First year after entry } \\
(p=1)\end{array}$ & $\begin{array}{c}0.052 \\
(0.060)\end{array}$ & $\begin{array}{l}-0.008 \\
(0.056)\end{array}$ & $\begin{array}{l}-0.115 \\
(0.309)\end{array}$ & $\begin{array}{c}0.028 \\
(0.070)\end{array}$ & $\begin{array}{l}-0.007 \\
(0.064)\end{array}$ & $\begin{array}{l}-0.307 \\
(0.407)\end{array}$ & $\begin{array}{c}0.018 \\
(0.104)\end{array}$ & $\begin{array}{l}-0.073 \\
(0.100)\end{array}$ & $\begin{array}{l}-0.107 \\
(0.520)\end{array}$ \\
\hline $\begin{array}{l}\text { Second year after entry } \\
(p=2)\end{array}$ & $\begin{array}{c}0.156^{* *} \\
(0.074)\end{array}$ & $\begin{array}{c}0.138 * * \\
(0.067)\end{array}$ & $\begin{array}{l}0.668 * \\
(0.402)\end{array}$ & $\begin{array}{l}0.139 * \\
(0.083)\end{array}$ & $\begin{array}{l}0.125^{*} \\
(0.074)\end{array}$ & $\begin{array}{c}0.808 \\
(0.499)\end{array}$ & $\begin{array}{c}0.238 \\
(0.146)\end{array}$ & $\begin{array}{c}0.211 \\
(0.138)\end{array}$ & $\begin{array}{l}1.124 \\
(0.757)\end{array}$ \\
\hline $\begin{array}{l}\text { Third year after entry } \\
(p=3)\end{array}$ & $\begin{array}{c}0.198 * * \\
(0.077)\end{array}$ & $\begin{array}{l}0.131^{*} \\
(0.071)\end{array}$ & $\begin{array}{c}0.629 \\
(0.408)\end{array}$ & $\begin{array}{l}0.201 * * \\
(0.085)\end{array}$ & $\begin{array}{c}0.105 \\
(0.077)\end{array}$ & $\begin{array}{c}0.718 \\
(0.512)\end{array}$ & $\begin{array}{c}0.001 \\
(0.181)\end{array}$ & $\begin{array}{l}-0.094 \\
(0.175)\end{array}$ & $\begin{array}{l}-0.424 \\
(0.893)\end{array}$ \\
\hline $\begin{array}{l}\text { Fourth year after entry } \\
(p=4)\end{array}$ & $\begin{array}{l}0.273^{* * * *} \\
(0.084)\end{array}$ & $\begin{array}{c}0.212 * * * \\
(0.076)\end{array}$ & $\begin{array}{l}1.848 * * * \\
(0.449)\end{array}$ & $\begin{array}{l}0.219 * * \\
(0.091)\end{array}$ & $\begin{array}{l}0.132 * \\
(0.080)\end{array}$ & $\begin{array}{c}2.046^{* * *} \\
(0.576)\end{array}$ & $\begin{array}{c}0.404 \\
(0.356)\end{array}$ & $\begin{array}{l}0.473^{*} \\
(0.254)\end{array}$ & $\begin{array}{l}2.747^{*} \\
(1.267)\end{array}$ \\
\hline
\end{tabular}

Note: Standard errors are clustered at individuals. $\left.*^{* *}\right)(* * *)$ indicate significance at the $10(5)(1)$ percent levels. 1000 NOK = 167 (based on exchange rate April 2014$)$

Number of observations: Column 1-3: 11,567,275; Column IV-VI: 9,953,115; Column VII-IX: 1,451,965.

Control variables included in all models: See note to Table 5. 


\subsection{Robustness across samples and subgroups}

How robust are these results? In this sub-section, we look at how the key estimates change when we expand the analysis population to include persons with somewhat higher earnings in the base year (or in the two years prior to the base year), as discussed in Section 4. In addition, given the large fraction of immigrants participating in the program, we estimate separate models for natives and immigrants. In these exercises, we focus on the outcomes of employment and log labor earnings only.

We first re-estimate the model based on a much wider definition of the risk-population increasing the sample size by around $65 \%$. This is done by raising the upper earnings threshold in the base-year to NOK 340,000 (57,000 \$). The results from this exercise are presented in Table 6, Columns I-III. The results are similar to those reported in Table 5. The main difference is that the estimated employment and earnings effects 2-4 years after QP entry become a bit larger and also more statistically significant. Based on the larger sample, we also estimate separate models for natives and immigrants. The results for natives are in line with the results reported for the complete population; see Table 6, Columns IV-VI. The results for immigrants also display a similar pattern, although they are much more unstable and subject to statistical uncertainty. Hence, we do not really have sufficient information in the data to draw any firm conclusions regarding possible effect heterogeneity.

\subsection{Endogenous migration?}

As discussed in Section 3, a causal interpretation of our estimates hinges on the assumption that persons' addresses (municipalities) up to (and including) 2007 are exogenous. Since the QP program was legislated in June 2007, there was a short window of opportunity during the autumn of 2007 whereby would-be QP participants could self-select into municipalities with early (2008) QP implementation. On average, around $11 \%$ the risk-group population move across municipalities each year, but we see no pattern of increased migration during the period in question. To nevertheless check the sensitivity of our estimates with respect to endogenous migration, we re-estimate the models presented in Section 5.2, but this time we tie each base-year observation to the last years' ( $t$-1) municipality (i.e., we disregard migrations that occurred between $t-1$ and $t$ ). This way, we eliminate the possibility of an endogeneity problem, but at the cost of inducing more measurement error into the model. The results of this exercise are presented in Table 7. As it turns out, the estimates change very little, suggesting that endogenous migration is not a big issue in the present context. 
Table 7. Estimation results with last year's address used to identify municipality (dataset with low earnings threshold). Instrumental Variables estimates (Eq. 4) (clustered standard errors in parentheses)

\begin{tabular}{ccc} 
I & II & III \\
\hline Employment & Employment & Log labor earn- \\
$(>85,000$ NOK $)$ & $(>170,000$ NOK $)$ & ings \\
\hline
\end{tabular}

\section{Effects of QP}

Same year $(p=0)$

$-0.050$

$(0.080)$

0.024

(0.068)

0.139

Second year after entry $(p=2)$

Third year after entry $(p=3)$

Fourth year after entry $(p=4)$
(0.087)

$0.158^{*}$

$(0.088)$

$0.194 *$

(0.099)
$-0.025$

$(0.070)$

$-0.066$

$(0.063)$

0.065

(0.078)

0.086

$(0.080)$

0.100

(0.088)
0.102

$(0.432)$

$-0.252$

(0.354)

0.604

(0.473)

0.341

(0.471)

$1.348^{* *}$

(0.533)

Note: Standard errors are clustered at individuals. ${ }^{*}(* *)(* * *)$ indicate significance at the $10(5)(1)$ percent levels. $1000 \mathrm{NOK}=167$ \$ (based on exchange rate April 2014). Number of observations: 6,903,650.

Control variables included in all models: See note to Table 5.

\subsection{Benefits versus costs}

Our analysis indicates that QP to some extent has accomplished its aims of helping hard-toemploy persons back to (or into) work. However, the program has also been costly. Have the benefits outweighed the costs? Based on the admittedly highly uncertain point estimates from the baseline model (Table 5), we calculate that the overall increase in net (after tax) transfers generated in the QP participation period (defined as the entry year plus the two subsequent years) amounts to approximately 50,000 NOK (8,300 \$). In addition, the increased administrative costs associated with fewer clients per caseworker (see the introduction) also amount to around 50,000 NOK. Adding a $20 \%$ marginal cost of public funds and leaving out the pure transfer component, these numbers imply a direct social cost of 70,000 NOK (11,700 \$) for each participant. Moreover, labor earnings are estimated to decline by approximately 55,000 NOK cumulatively over the first two years (including the entry year), as a result of lock-in effects. On the benefit side, labor earnings start to increase from the second year after entry, and reach a positive annual QP effect of 50,000 NOK after four years. However, the cumulative earnings gain in this period $(67,000 \mathrm{NOK})$ still falls short of the initial costs. Hence, for this particular cost-benefit assessment to come out with a positive number, we need to assume that the favorable earnings and employment effects to some extent persist after the fourth year. If we do extrapolate the estimated forth-year effects to subsequent years, our highly simplified cost-benefit calculation breaks even in the fifth year, and becomes positive thereafter. 
In addition to the costs and benefits discussed here, there will of course also be costs and benefits associated with the particular activities that the QP participants take part in, which - as described above - ranges from medical rehabilitation to fulltime work. Since we do not have any specific information about individual QP activities, nor about the activities that would have prevailed without QP, we are not able to provide precise assessment of these cost-benefit components. However, statistics reported by Statistics Norway, based on information collected from the municipalities, indicate that work is the dominating activity. For example, among those who entered QP in 2009, as much as $78 \%$ participated in some form of employment in 2010 as part of their individual QP plan. ${ }^{10}$ This presumably implies that value is generated, though probably at some costs associated with individual support and workplace adaptations.

Additional favorable effects of QP may come from peer influences. Recent empirical studies have indicated that welfare dependency is contagious within social networks; see, e.g., Rege et al. (2012) and Markussen and Røed (forthcoming). Hence, if QP succeeds in moving at least some persons from welfare to work, we may expect to see subsequent knock-on effects among their peers.

An important point to bear in mind is that a main aim of QP was to reduce poverty. Our estimation results indicate that the overall level of take-home earnings was raised for all years after entry, with a possible exception for the third year after entry in which the increased transfer level has been tapered off while the favorable earnings effects are still small. Hence, poverty problems appear to have been alleviated by the program.

\section{Conclusion}

The main conclusion of our analysis is that the combination of activation requirements and economic generosity appears to have had the intended effect of helping a very hard-to-employ group of persons back to (or into) work in Norway. Two years after entry into the Qualification Program (QP), we identify indications of a positive effect on the probability of having obtained at least some paid employment, and the effect increases in subsequent years. Four years after entry, our estimates indicate that the employment probability is raised by as much as 18 percentage points, ceteris paribus. Effect estimates of this order appear robust across different samples and subgroups. The statistical uncertainty associated with each single esti-

\footnotetext{
${ }^{10}$ These numbers are available from «Statistikkbanken» (https://www.ssb.no/statistikkbanken).
} 
mate is large, however (standard errors around 8-9 percentage points), hence the point estimates should be interpreted with care.

Although most of the additional jobs are small, at least to start with, they may represent important stepping-stones into regular employment for a group of persons who in the absence of the program most likely would have had labor force participation rates close to zero. Together with the structured and active everyday life implied by the program itself this may also have built up a work habit among the participants with possible knock-on effects on the participants' peers. Whether the gains identified in this paper are sufficient to compensate for the costs depends on the extent to which the moderately increased labor earnings can be expected to last or perhaps even become a first step toward full employment, which is too early to say based on our data.

\section{References}

Aakvik, A., Heckman, J., and Vytlacil, E. (2005) Estimating Treatment Effects for Discrete Outcomes when Responses to Treatment Vary: An Application to Norwegian Vocational Rehabilitation Programs. Journal of Econometrics, Vol. 125, 15-51.

Angrist, J., Imbens, G. W. and Rubin, D. B. (1996) Identification of Causal Effects Using Instrumental Variables. Journal of the American Statistical Association, Vol. 91, 444-455.

Ashenfelter, O. (1978) Estimating the Effect of Training Programs on Earnings. Review of Economics and Statistics, Vol. 60, 47-50.

Calvó-Armengol, A. and Jackson, M. O. (2004) The Effects of Social Networks on Employment and Inequality. American Economic Review, Vol. 94, No. 3, 426-454

Card, D., Kluve, J., and Weber, A. (2010) Active Labour Market Policy Evaluations: A Metaanalysis. The Economic Journal, Vol. 120, F452-F477.

Christensen, T., Fimreite, A. L., and Lægreid, P. (2013) Joined-Up Government for Welfare Administration Reform in Norway. Public Organization Review, forthcoming.

Dasgupta, P. (1997) Nutritional Status, the Capacity for Work, and Poverty Traps. Journal of Econometrics, Vol. 77, 5-37.

Dasgupta, P. and Ray, D. (1986) Inequality as a Determinant of Malnutrition and Unemployment: Theory, Economic Journal, Vol. 96, 1011-1034.

Dasgupta, P. and Ray, D. (1987) Inequality as a Determinant of Malnutrition and Unemployment: Policy, Economic Journal, Vol. 97, 177-188.

Fevang, E., Hardoy, I., and Røed, K. (2013) Getting Disabled Workers Back to Work: How Important Are Economic Incentives? IZA Discussion Paper No. 7137. 
Kostøl, A. R., and Mogstad, M. (2014) How Financial Incentives Induce Disability In-surance Recipients to Return to Work. American Economic Review, forthcoming.

Kluve, J., Card, D., Fertig, M., Góra, M., Jacobi, J., Jensen, P., Leetmaa, R., Nima, L., Patacchini, E., Schaffner, S., Schmid, C. M., van der Klaauw, B., and Weber, A. (2007) Active Labor Market Policies in Europe - Performance and Perspectives. Springer-Verlag Berlin and Heidelberg $\mathrm{GmbH} \& \mathrm{Co}$.

Frölich, M., Hesmati, A., and Lechner, M. (2004) A Microeconomic Evaluation of Rehabilitation of Long-term Sickness in Sweden. Journal of Applied Econometrics, Vol. 19, 375-396.

Gubrium, E. K. and Lødemel, I. (2014) “Not Good Enough”: Social Assistance and Shaming in Norway. Chapter 5 in Gubrium, E. K., Pellissery, S., and Lødemel, I. (Eds.): The Shame of It. Global Perspectives on Anti-Poverty Policies. Policy Press. Bristol, UK.

Krueger, A. B. and Meyer, B. D. (2002) Labor Supply Effects of Social Insurance. In Auerbach, A. J. and Feldstein, M. (eds.) Handbook of Public Economics, Vol. 4. Elsevier Science, NorthHolland, 2002; 2327-92.

Markussen, S. and Røed, K. (forthcoming) Social Insurance Networks. Journal of Human Resources.

Markussen, S. and Røed, K. (2014) The Impacts of Vocational Rehabilitation. IZA Discussion Paper No. 7892.

Moffitt, R. (2007) Welfare Reform: The US Experience. Swedish Economic Policy Review, Vol. 14, No. 2, 11-48.

Mullainathan, S. and Shafir, E. (2013) Scarcity: Why Having Too Little Means so Much. Time Books, Henry Holt and Company, New York.

Rege, M., Telle, K., and Votruba, M. (2012) Social Interaction Effects in Disability Pension Participation - Evidence from Plant Downsizing. Scandinavian Journal of Economics Vol. 114, No. 4, 1208-1239.

Røed, K. (2012) Active Social Insurance. IZA Journal of Labor Policy, Vol. 1:8 (doi:10.1186/21939004-1-8).

Røed, K. and Raaum, O. (2006) Do Labour Market Programmes Speed up the Return to Work? Oxford Bulletin of Economics \& Statistics, Vol. 68, No. 5, 541-68

Røed, K. and Westlie, L. (2012) Unemployment Insurance in Welfare States: The Impacts of Soft Duration Constraints. Journal of the European Economic Association, Vol. 10, No. 3, 518554.

Røed, K. and Zhang, T. (2003) Does Unemployment Compensation Affect Unemployment Duration? Economic Journal, Vol. 113, 190-206.

Røed, K. and Zhang, T. (2005) Unemployment duration and economic incentives - A quasi randomassignment approach. European Economic Review , Vol. 49, 1799-1825.

Schafft, A. and Spjelkavik (2011) Evaluering av Kvalifiseringsprogrammet (Evaluation of the Quali- 
fication Program). AFI-rapport 4/2012.

Shah, A. K., Mullainathan, S., and Sharif, E. (2012) Some Consequences of Having Too Little. Science, Vol. 338, 682-685,

Walker, R., Kyomuhendo, G. B., Chase, E., Choudhry, S., Gubrium, E. K, Nicola, J. Y., Lødemel, I., Mathew, L. Mwiine, A., Pellissery, S. and Ming, Y. (2013) Poverty in Global Perspective: Is Shame a Common Denominator? Journal of Social Policy, Vol. 42, No. 2, 215-233. 